\title{
Implicações do Período de Crescimento na Composição Química e Digestão dos Tecidos de Cultivares de Capim-Elefante (Pennisetum purpureum Schumach.)
}

\author{
Francisco Carlos Deschamps ${ }^{1}$
}

\begin{abstract}
RESUMO - No presente trabalho foram medidas, ao longo de 126 dias de crescimento, as principais modificações na composição química e na digestibilidade da matéria seca (MS) de três cultivares (Empasc-307-Testo, Empasc-309-Areia e Roxo) de capim-elefante (Pennisetum purpureum Schumach.). A produção e a qualidade destas gramíneas forrageiras tropicais foram determinadas, em parte, pelo período de crescimento. Com o alongamento do período de crescimento, as plantas apresentaram maior altura e produção de MS, aumentando a concentração de fibra em detergente neutro (FDN) e lignina, na medida em que ocorreu forte redução na digestibilidade da MS e FDN. A contribuição do colmo na produção total de MS acentuou-se, chegando ao final do período com relação folha:colmo de 35:65\%. Em estádio mais avançado de crescimento, mesmo apresentando semelhante concentração de lignina, a digestibilidade do colmo foi inferior à da folha. A perda de qualidade, medida pela redução na digestibilidade, observada com o envelhecimento do capim-elefante está relacionada ao espessamento e lignificação da parede celular, acompanhada por redução na proporção de folhas na produção total de MS. No colmo, além da lignina, outras barreiras contribuem para a redução da digestibilidade.
\end{abstract}

Palavras-chave: digestão, forragens, herbívoros, lignina, parede celular, ruminantes

\section{Effects of Growing Periods on Digestion and Chemical Composition of Elephant Grass Cultivars Tissues}

\begin{abstract}
In the present work, the chemical composition changes and dry matter (DM) digestibility of three cultivars (Empasc307-Testo, Empasc-309-Areia and Roxo) of elephant grass (Pennisetum purpureum Schumach.), were measured through a growing period of 126 days. The production and quality of tropical forage grasses were determined, in part, by the growing period. The plants showed greater height and dry matter accumulation, increasing the neutral detergent fiber (NDF) and lignin concentrations and substantially reducing DM and NDF digestibility levels, with longer growing periods. The stem contribution with the total DM production increased with time, reaching leaf:stem ratio of 35:65 \% by the end of the growing period. At advanced growth stage, even with similar lignin concentration, the stem digestibility was lower than that of leaves. The loss of quality measured as a decrease in the digestibility, observed in elephant grass at advanced growth stage, was related to the thickness and lignification of the cell wall, followed by a reduction in the leaf:stem ratio. Other factors, besides lignin, contributed for reducing digestibility of stem.
\end{abstract}

Key Words: cell wall, digestion, forages, herbivores, lignin, ruminants

\section{Introdução}

Em estudos com plantas forrageiras, o envelhecimento dos tecidos vegetais e a conseqüente redução na digestibilidade são fenômenos intimamente associados. Esta relação, observada mais intensamente em gramíneas tropicais, contribui decisivamente para limitar sua utilização como alimento para ruminantes. Com o avanço da maturidade fisiológica, as forrageiras acumulam maior quantidade de matéria seca, ganhando altura pelo alongamento do caule e folhas. Além disso, outras alterações, como a modificação na relação folha:colmo e a de material verde:morto, são observadas. Nos tecidos, observa-se a redução do lume das células, pelo espessamento da parede celular, com a conseqüente ampliação da área ocupa- da pelo tecido vascular lignificado (WILSON, 1993; ALVES DE BRITO, 1997). Já o incremento na deposição de lignina e a redução no teor de proteína bruta parecem ser as principais alterações químicas observadas na composição da matéria seca.

O capim-elefante, por seu grande potencial produtivo e sua adaptação em regiões tropicais, constitui-se em importante alternativa forrageira a ser utilizada na alimentação de ruminantes destinados à produção de carne e leite (HILLESHEIN, 1988; HILLESHEIN, 1993; e VEIGA, 1994). A diversidade genética e sua qualidade como forrageira contribuem para que possa ser manejada sob corte ou pastejo direto (HILLESHEIN, 1988; HILLESHEIN, 1993; VEIGA, 1994; e ALMEIDA, 1997). Mesmo com grande potencial produtivo, o capim-elefante 
apresenta elevado grau de variação em seus parâmetros de qualidade. Esta variação é decorrente não somente da diversidade genética observada nesta espécie, mas também das modificações que ocorrem com o envelhecimento dos tecidos ou o período de crescimento da planta. Como gramínea tropical de via fotosssintética $\mathrm{C}_{4}$, o capim-elefante apresenta grande capacidade de assimilação da energia solar e, portanto, de acumulação de matéria seca (LAETSCH, 1974; BOGDAN, 1977; e JACQUES, 1994). Entretanto, este metabolismo acelerado resulta em modificações na estrutura e composição da parede celular, que comprometem a digestibilidade do material. Assim, a associação do conhecimento da diversidade genética com práticas de manejo adequadas é fundamental para que se aproveite ao máximo o potencial forrageiro do capim-elefante. Parte desse conhecimento refere-se ao estabelecimento das principais características químicas e anatômicas dos tecidos vegetais, o qual é fundamental para se estabelecerem as recomendações de manejo.

A fisiologia digestiva dos ruminantes determina que a digestão dos alimentos dependa, principalmente, da íntima associação entre a partícula de alimento e os microorganismos ruminais (CHESSON, 1993; WEIMER, 1993). Portanto, barreiras físicas ditadas pelo arranjo das células ao longo do tecido, ou químicas, decorrentes da composição e arranjo dos componentes da parede celular, são determinantes no processo de digestão nos ruminantes.

Em Santa Catarina, alguns acessos de capimelefante coletados ao longo do Vale do Itajaí apresentaram características distintas e elevado potencial produtivo (SALERNO et al., 1990; AUGUSTIN e TCACENCO, 1993). Entre 55 acessos avaliados ao longo de três anos, o Empasc-307-Testo (acesso IJ-7136) e o Empasc-309-Areia (acesso IJ-7127) posicionaramse entre os oito melhores materiais em termos de produção de matéria seca (SALERNO et al., 1990).

No presente estudo, três cultivares de capimelefante (Empasc-307-Testo, Empasc-309-Areia e Roxo) foram acompanhados ao longo de 126 dias de crescimento, com o objetivo de determinar as principais modificações nos parâmetros químicos do tecido vegetal e suas relações com a digestibilidade.

\section{Material e Métodos}

\section{Material botânico}

Foram utilizados três cultivares de capim-elefante (Pennisetum purpureum Schumach.), Empasc307-Testo, Empasc-309-Areia e Roxo, os quais já se encontravam plenamente estabelecidos junto à Estação Experimental de Itajaí (EPAGRI S/A), Itajaí - SC (lat. 2654'28' S, long. 48³9'43”'W, altitude $5 \mathrm{~m}$ ). O delineamento experimental foi em blocos ao acaso com cinco repetições, acompanhando-se o crescimento das plantas até 126 dias. O corte de emparelhamento foi realizado em 10/11/93 e a primeira coleta efetuada quatro semanas após, sendo os demais cortes realizados a cada duas semanas até completar 18 semanas (126 dias) de crescimento, totalizando, assim, oito cortes. As parcelas apresentaram área útil de $2 \mathrm{~m}^{2}$, sendo os cortes realizados à altura de $20 \mathrm{~cm}$ do solo. A altura média das plantas na parcela foi determinada por intermédio de uma régua adaptada para a medida. Após o corte, procedeu-se à separação manual das frações botânicas correspondentes ao colmo e às folhas. O material foi submetido à secagem em estufa de ar forçado, com temperatura ajustada para $55^{\circ} \mathrm{C}$, até a obtenção de peso constante. Após a secagem, o material foi moído em moinho tipo Wiley dotado de peneira de $2 \mathrm{~mm}$, quando destinado a digestão in situ, e $1 \mathrm{~mm}$, para as análises químicas.

Análises químicas

A proteína bruta foi determinada pelo método Kjelhdahl - semi-micro, em que o teor de N determinado é multiplicado por $6,25(\mathrm{~N} * 6,25)$ (SILVA, 1981). Para a determinação da fibra em detergente neutro (FDN), adotaram-se modificações no procedimento do método de Van Soest. Na preparação do detergente neutro, utilizou-se a marcha descrita por SILVA (1981), sem a adição de sulfito, dispensando o uso da decalina. Cerca de $200 \mathrm{mg}$ de amostra foram acondicionados em saquinho de nylon medindo $5 \times 5 \mathrm{~cm}$, com porosidade média de $45 \mu \mathrm{m}$. Até trinta saquinhos foram acondicionados em um saco maior, confeccionado do mesmo material, contendo em seu interior contrapeso de porcelana, para evitar a flutuação das amostras contidas nos saquinhos menores. Este conjunto foi acomodado em um erlenmeyer de boca larga, quando se adicionaram $500 \mathrm{~mL}$ de solução 
1360 Rev. bras. zootec.

detergente neutro, selando-se a boca do frasco com papel alumínio. Este conjunto foi então levado para uma autoclave de bancada, com capacidade para 20 litros, na qual foi adaptado um sistema de controle de tempo (ajustável de 1 a 90 minutos), que atua integrado com o termostato, de modo que o tempo somente começa a ser contado quando a temperatura de operação é atingida. Ao final do tempo de operação, o termostato automaticamente desliga todo o sistema, aguardando-se o resfriamento do conjunto para permitir a abertura e retirada do material processado. A temperatura ajustada na autoclave foi de $120^{\circ} \mathrm{C}$, com variação de $\pm 1^{\circ} \mathrm{C}$, sendo o tempo de operação de 40 minutos. Este tempo foi determinado em ensaios prévios utilizando-se azevém e bagaço de cana como amostras experimentais. A adoção deste procedimento, com a utilização da autoclave, permite executar até 120 amostras por operação, resultando em grande produtividade no laboratório, com sensível economia de reagentes.

Para a determinação da lignina, adotou-se o método descrito por THEANDER e WESTERLUND (1986) e HATFIELD et al. (1994), por intermédio do qual amostras de $100 \mathrm{mg}(1 \mathrm{~mm})$ foram submetidas à pré-hidrólise, durante uma hora, à temperatura ambiente, com a adição de 1,5 mL de ácido sulfúrico $72 \%$ (12M). Em seguida, a solução foi diluída para 0,4 M com a adição de 43,5 mL de água destilada, quando a amostra foi submetida à nova hidrólise (1 hora, 120 $\pm 1^{\circ} \mathrm{C}$ ), na mesma autoclave já descrita e utilizada para a determinação de FDN. Após a hidrólise, o material foi filtrado em filtro de fibra de vidro (24 mm - Ø), sendo o material retido considerado lignina, também chamada de lignina de Klason (TAPPI - Método T222/os-74). No presente trabalho, não foram feitos os descontos referentes à contribuição das cinzas/sílica contidas neste resíduo. No filtrado da hidrólise, completou-se o volume para $100 \mathrm{~mL}$, sendo que uma alíquota de $5 \mathrm{~mL}$ foi armazenada para posterior determinação de açúcares neutros por HPLC e ácidos por espectrofotometria.

\section{Digestão ruminal}

Para os ensaios de digestão ruminal, foi adotada a técnica do saco de nylon com tempo de incubação fixado em 48 horas, usando-se três bovinos holandêses adultos, com peso vivo de $550 \mathrm{~kg}$ e dotados de cânula ruminal. Cerca de $300 \mathrm{mg}$ de amostra foram acondicionados em saquinhos de nylon medindo $5 \times 5 \mathrm{~cm}$, com porosidade média de $45 \mu \mathrm{m}$. Até cinco saquinhos foram acondicionados em um saco maior, confecci- onado em nylon, o qual era preso a um pequeno pedaço de cano de PVC de 1 polegada, dotado de contrapeso para facilitar o afundamento para o saco ventral do rúmen. Este conjunto estava preso à borda da fístula por fio de nylon, medindo cerca de $50 \mathrm{~cm}$.

\section{Resultados e Discussão}

A digestão nos ruminantes é um processo complexo, já que resulta da interação de diferentes formas vivas, como planta, animal e microorganismos ruminais. Entender e dimensionar a contribuição de cada uma dessas formas no processo de digestão permanece sendo um desafio a ser superado. A alimentação ainda é o item de maior participação nos custos de produção dos ruminantes, na qual se pode mais prontamente alterar o desempenho produtivo dos animais. A possibilidade dos ruminantes aproveitarem os nutrientes presentes nas forrageiras é uma vantagem que os diferencia das demais espécies animais. Portanto, conhecer as particularidades dos componentes da alimentação volumosa dos ruminantes, como no caso do capim-elefante, parece ser um bom caminho para que se possa maximizar a produção animal.

Vários estudos têm comprovado que, no capimelefante, características como altura da planta, relação colmo:folha, adubação, regime de corte, altura de corte, entre outros, apresentam relação direta com a produtividade e sua qualidade como forragem (ANDRADE e GOMIDE, 1971; CORSI, 1972; GONÇALVES, 1975; HILLESHEIN, 1988; HILLESHEIN, 1993; e VEIGA, 1994). Ao se utilizar o termo qualidade ou valor nutritivo em forrageiras, deve-se ter em mente que a definição dos limites de sua abrangência não é tarefa fácil. Muitos estudos têm utilizado as medidas de proteína bruta e digestibilidade aparente como indicadores de qualidade, sem relacionar, entretanto, outras modificações profundas dos tecidos, como anatomia e composição química.

No presente estudo, foi possível determinar as principais modificações que ocorrem nos tecidos de cultivares de capim-elefante, à medida que o material se torna mais velho. As condições climáticas ocorridas ao longo do período experimental (Figura 1) foram bastante favoráveis ao crescimento e à acumulação de matéria seca nos três cultivares estudados. A capacidade de conversão de energia solar em matéria seca apresentada por estes materiais foi marcante, como pode ser observado na Figura 2. O capim-elefante é uma gramínea que apresenta forte produção estacional, concentrando cerca de $70 \%$ de 
sua produção no período de verão. Em estudos realizados ao longo de três anos, em três locais de Santa Catarina, SALERNO et al. (1990) determinaram que os cultivares TESTO e AREIA concentraram 76,4 e $71,7 \%$ de sua produção no verão, demonstran- do sua grande capacidade em aproveitar a energia solar e a temperatura disponíveis naquela época.

$\mathrm{O}$ aumento de produção de matéria seca foi acompanhado pelo incremento na altura das plantas (Tabela 1). Com quatro semanas de crescimento, o

Tabela 1 - Efeito do período de crescimento sobre algumas variáveis observadas em três cultivares de capim-elefante

Table 1 - Effects of growing period on some variables observed in three elephant grass cvs

\begin{tabular}{|c|c|c|c|c|c|c|}
\hline \multirow{3}{*}{$\begin{array}{l}\text { Parâmetro } \\
\text { Parameter }\end{array}$} & & \multicolumn{4}{|c|}{$\begin{array}{c}\text { Dias de crescimento } \\
\text { Days of growing }\end{array}$} & \multirow{3}{*}{126} \\
\hline & & \multirow[t]{2}{*}{28} & \multirow[t]{2}{*}{42} & \multirow[t]{2}{*}{56} & \multirow[t]{2}{*}{84} & \\
\hline & & & & & & \\
\hline & & \multicolumn{5}{|c|}{ Cv.TESTO } \\
\hline \multicolumn{2}{|l|}{ Altura (cm) } & 99 & 153 & 185 & 229 & 289 \\
\hline \multicolumn{7}{|l|}{ Height } \\
\hline Relação folha:colmo (\% MS) & Folha & 54,3 & 53,0 & 51,5 & 41,2 & 36,5 \\
\hline Leaf:stem ratio (DM \%) & Colmo & 45,7 & 47,0 & 48,5 & 58,8 & 63,5 \\
\hline $\mathrm{FDN}^{1}(\%)$ & Folha & 71,1 & 74,3 & 73,3 & 78,5 & 75,2 \\
\hline$N D F$ & Colmo & 64,6 & 73,0 & 74,1 & 81,1 & 81,4 \\
\hline Degradação da FDN (\%) ${ }^{2}$ & Folha & 65,0 & 59,0 & 52,2 & 51,8 & 44,6 \\
\hline NDF degradation & Colmo & 63,5 & 59,5 & 46,6 & 35,8 & 23,7 \\
\hline Digestibilidade da MS $(\%)^{2}$ & Folha & 72,0 & 65,8 & 61,5 & 56,4 & 53,9 \\
\hline DM degradation & Colmo & 76,3 & 69,1 & 57,7 & 46,2 & 37,7 \\
\hline $\operatorname{Lignina}(\%)^{3}$ & Folha & 13,7 & 14,4 & 16,0 & 17,7 & 18,7 \\
\hline \multirow[t]{2}{*}{ Lignin } & Colmo & 9,3 & 10,9 & 12,4 & 15,6 & 17,9 \\
\hline & & \multicolumn{5}{|c|}{ Cv. AREIA } \\
\hline Altura (cm) & & 48 & 103 & 142 & 198 & 264 \\
\hline \multicolumn{7}{|l|}{ Height } \\
\hline Relação folha:colmo (\% MS) & Folha & 72,7 & 63,3 & 60,9 & 39,2 & 36,5 \\
\hline Leaf:stem ratio (DM \%) & Colmo & 27,3 & 36,7 & 39,1 & 60,8 & 63,5 \\
\hline $\operatorname{FDN}(\%)^{1}$ & Folha & 58,6 & 67,2 & 72,2 & 76,3 & 75,9 \\
\hline$N D F$ & Colmo & 58,4 & 70,3 & 75,1 & 83,3 & 81,5 \\
\hline Degradação da FDN (\%) ${ }^{2}$ & Folha & 65,2 & 63,1 & 58,2 & 54,6 & 48,4 \\
\hline NDF degradation & Colmo & 54,5 & 59,1 & 52,1 & 40,2 & 26,4 \\
\hline Digestibilidade da MS $(\%)^{2}$ & Folha & 78,4 & 73,4 & 67,4 & 61,3 & 56,4 \\
\hline DM degradation & Colmo & 76,3 & 71,3 & 62,3 & 46,1 & 37,3 \\
\hline $\operatorname{Lignina}^{3}(\%)$ & Folha & 11,9 & 13,6 & 14,3 & 16,2 & 17,7 \\
\hline \multirow[t]{2}{*}{ Lignin } & Colmo & 8,8 & 10,1 & 11,5 & 16,0 & 18,2 \\
\hline & & \multicolumn{5}{|c|}{ Cv.ROXO } \\
\hline Altura (cm) & & 65 & 108 & 151 & 197 & 267 \\
\hline \multicolumn{7}{|l|}{ Height } \\
\hline Relação folha:colmo (\% MS) & Folha & 65,1 & 61,3 & 56,2 & 43,1 & 33,5 \\
\hline Leaf:stem ratio (DM \%) & Colmo & 34,9 & 38,7 & 43,8 & 56,9 & 66,5 \\
\hline $\operatorname{FDN}^{1}(\%)$ & Folha & 60,3 & 66,5 & 69,5 & 73,6 & 69,9 \\
\hline$N D F$ & Colmo & 59,9 & 70,4 & 71,8 & 76,6 & 81,3 \\
\hline Degradação da FDN (\%) ${ }^{2}$ & Folha & 63,8 & 55,4 & 57,3 & 54,3 & 38,0 \\
\hline NDF degradation & Colmo & 56,1 & 56,9 & 50,3 & 33,9 & 25,3 \\
\hline Degradação da MS (\%) ${ }^{2}$ & Folha & 76,7 & 68,6 & 67,8 & 60,7 & 54,3 \\
\hline DM degradation & Colmo & 75,9 & 70,0 & 64,5 & 49,2 & 38,3 \\
\hline $\operatorname{Lignina}^{3}(\%)$ & Folha & 13,8 & 15,1 & 15,8 & 18,5 & 20,0 \\
\hline Lignin & Colmo & 10,2 & 11,1 & 11,4 & 14,8 & 18,4 \\
\hline \multicolumn{7}{|c|}{$\begin{array}{l}\text { Folha (leaf); Colmo (stem). } \\
1 \text { Amostras submetidas à digestão em solucão detergente neutro por } 40 \text { minutos em autoclave }\left(120^{\circ} \mathrm{C}\right) \text {. }\end{array}$} \\
\hline $\begin{array}{l}1 \text { Amostras submetidas à digestão } \\
2 \text { Dados obtidos a partir da incubaçã } \\
\text { adultos dotados de cânula rumine }\end{array}$ & solução & gente & $\begin{array}{l}\text { por } 40 \\
\text { on, po }\end{array}$ & ras, uti & dave $(1$ & $\begin{array}{l}\left.{ }^{\circ} \mathrm{C}\right) \text {. } \\
\text { bovinos }\end{array}$ \\
\hline \multirow{2}{*}{\multicolumn{7}{|c|}{$\begin{array}{l}3 \text { Denominada de lignina de Klason, contendo, além da lignina, alguns elementos minerais e sílica. Para esta } \\
\text { determinação, as amostras, em duplicata, foram submetidas à pré-hidrólise em ácido sulfúrico } 12 \mathrm{M} \text { durante } \\
1 \text { hora. Após, o ácido foi diluído para } 0,4 \mathrm{M} \text { e o material submetido à nova hidrólise em autoclave de bancada } \\
\text { durante } 60 \text { minutos a } 120^{\circ} \mathrm{C} \text {. }\end{array}$}} \\
\hline & & & & & & \\
\hline 1 Samples were allotted to digestion in $n$ & l detergen & tion $(40$ & $120^{\circ} \mathrm{C}$ & & & \\
\hline \multicolumn{7}{|c|}{$\begin{array}{l}2 \text { Data were obtained from the nylon bag technique with samples incubation ( } 48 \mathrm{~h}) \text { in three cannulated adults bovine. This residue } \\
\text { (Klason lignin) hold other minerals and silica beyond lignin. The samples were subjected to an acid hydrolysis } \\
\left(\mathrm{H}_{2} \mathrm{SO}_{4} 12 \mathrm{M}-1 \mathrm{~h} \text { at room temperature) and after the acid was diluted to } .4 \mathrm{M} \text { and hydrolysed again }\left(1 \mathrm{~h}-120^{\circ} \mathrm{C}\right) \text {. }\right.\end{array}$} \\
\hline
\end{tabular}


1362 Rev. bras. zootec.

cultivar AREIA apresentou menor altura inicial e o cultivar TEXTO, a maior, sendo observada pouca diferença entre os cultivares ao final do período de crescimento. A relação folha:colmo apresenta comportamento distinto entre os cultivares no estádio inicial de crescimento, tendendo a se estabilizar em 35:65 aos 126 dias de crescimento (Tabela 1). Aos 28 dias de crescimento, a maior parte do acúmulo de matéria seca observado no cultivar AREIA $(72,7 \%)$ advém do crescimento das folhas. Com mais folhas e menor altura das plantas na parcela, o cultivar AREIA pode se constituir em boa alternativa de uso em sistemas de pastejo direto. Esta característica favorável tem sido comprovada no sistema de produção de leite da EPAGRI - Estação Experimental de Itajaí (Itajaí, SC), onde, há cerca de 18 anos, o material tem persistido bem, quando utilizado sob pastejo rotacionado (HILLESHEIM et al., 1995).

Com a ampliação do período de crescimento, observa-se que a maior contribuição na deposição de matéria seca se deslocou rapidamente das folhas para o colmo (Tabela 1 e Figura 3). Paralelamente, muitas modificações foram observadas nos constituintes da parede celular, como, por exemplo, a fibra em detergente neutro (FDN). A medida de FDN tem sido utilizada para representar a quantidade de parede celular presente na amostra, ou, mais estritamente, a quantidade de celulose, hemicelulose, lignina e cinzas que compõe este complexo. Por outro lado, o que é solubilizado é tido como nutriente de elevado potencial de digestão (PELL et al., 1997). Observa-se que, nos três materiais, ocorre aumento no conteúdo de FDN, à medida que se amplia o período de crescimento (Tabela 1). Este aumento é determinado pelo espessamento da parede celular vegetal e pela redução do lume e conteúdo celular (WILSON, 1997; ALVES DE BRITO, 1997).

Concomitante à redução no conteúdo celular, observou-se queda no teor de proteína bruta tanto nas folhas como no colmo (Figura 4). HILLESHEIM
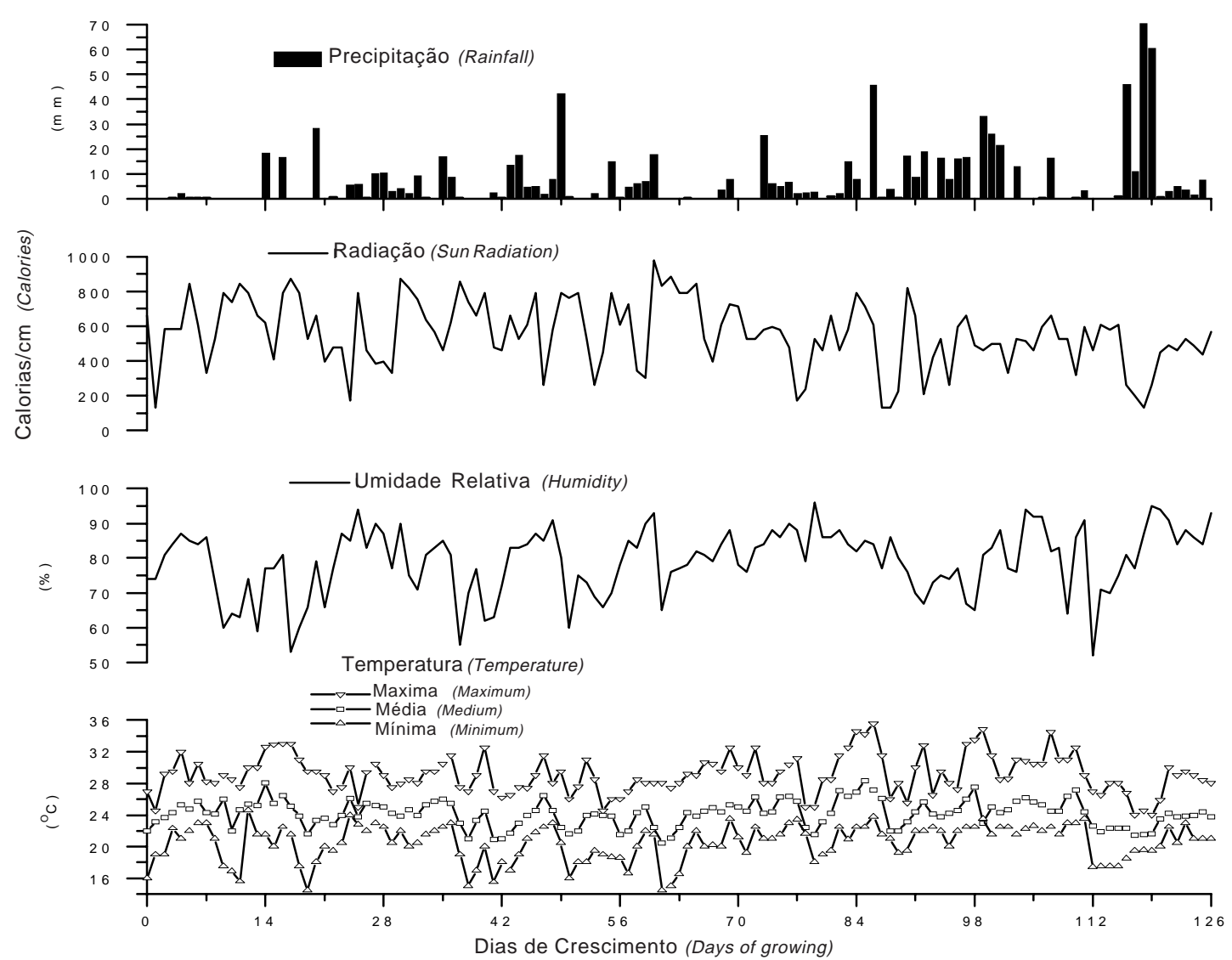

Figura 1 - Comportamento das variáveis climáticas observadas ao longo do período de 126 dias de crescimento, de três cultivares de capim-elefante.

Figure 1 - Climate variables observed through the growing period of 126 days for three elephant grass cvs. 
(1993) relata estudos em que cultivares de capim-

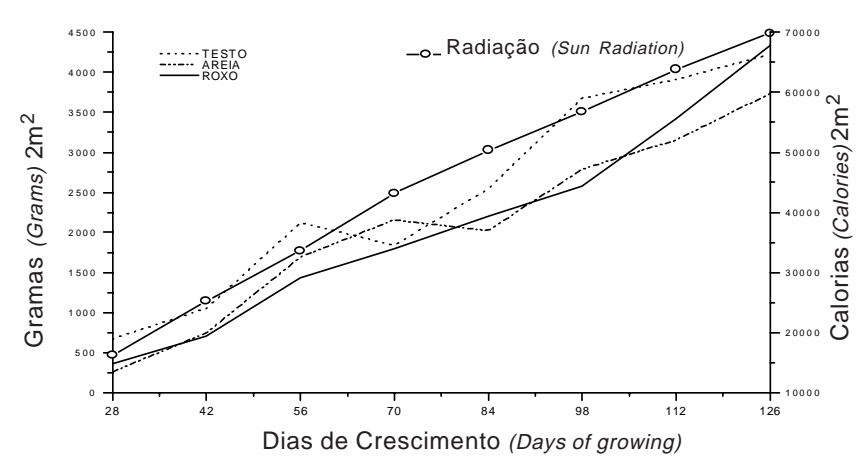

Figura 2 - Produção acumulada de matéria seca em três cultivares de capim-elefante e disponibilidade de radiação solar ao longo do período de crescimento de 126 dias.

Figure 2 - Accumulated dry matter production for three elephant grass cultivares, and sun radiation avaliable during the growing period of 126 days. elefante apresentam teor de proteína bruta na planta variando de 9,7 a 16,6\%, com quatro semanas, e 3,8 a 7,5\%, com 14 semanas. Pode-se observar que os teores de PB encontrados para os materiais estudados encontram-se nos limites descritos para outros cultivares de capim-elefante. De qualquer forma, o conteúdo de proteína bruta foi maior nas folhas que no colmo, como normalmente é observado nas gramíneas. Assim, pode-se inferir que, aproximadamente, até 56 dias de crescimento, as plantas de capim-elefante apresentam teores de proteína razoáveis para suprir a demanda mínima de $\mathrm{N}$ no ambiente ruminal. Considerando a utilização da planta como um todo, o teor médio de N é, em parte, garantido pela razoável relação folha:colmo apresentada pelos materiais (Tabela 1). Dietas com pouca disponibilidade de $\mathrm{N}(<10 \%$ PB) influem no desempenho animal. Isto é freqüentemente observado, quando os rumi-
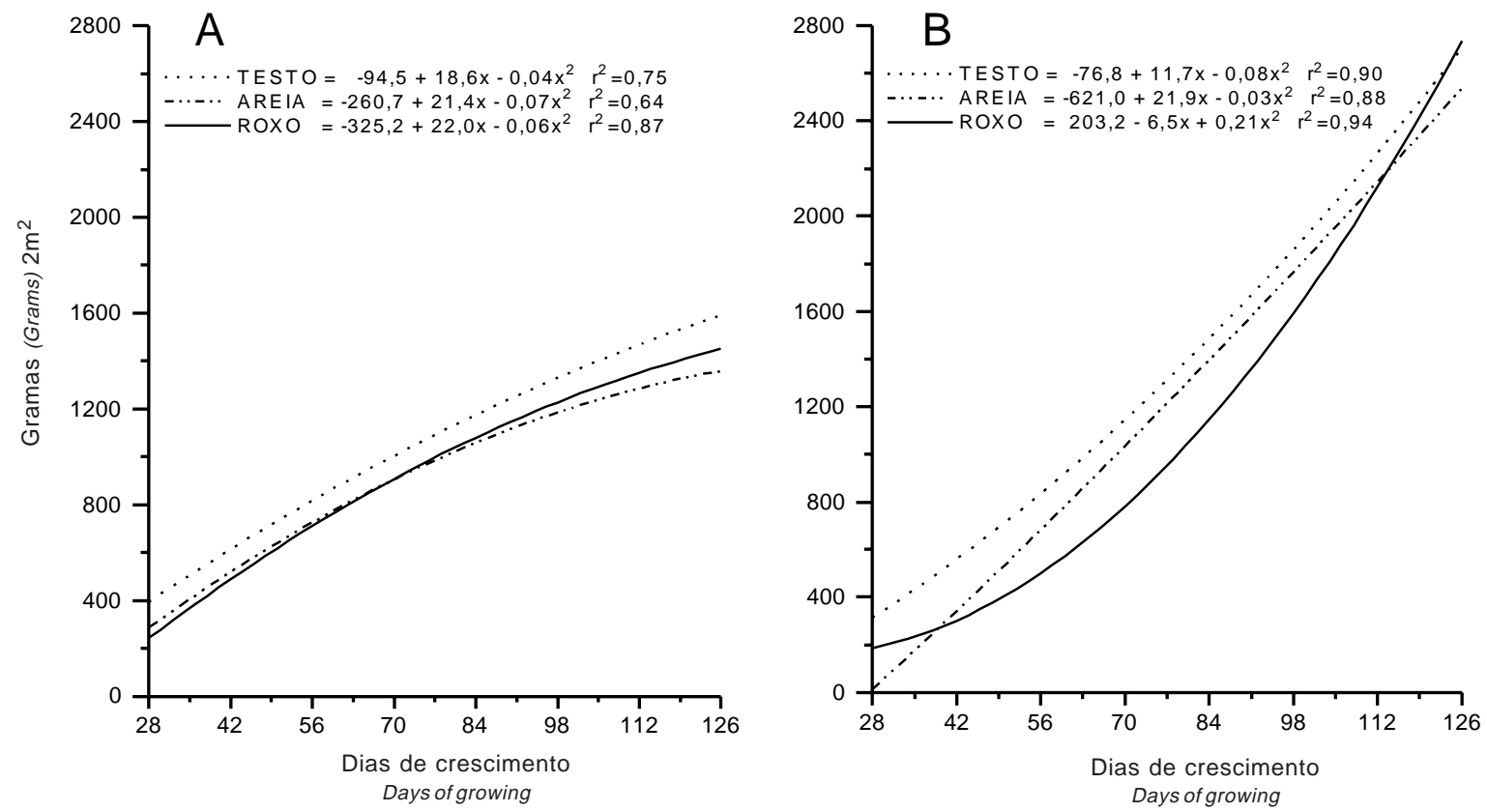

Figura 3 - Produção acumulada de matéria seca ao longo de 126 dias de crescimento, de três ecotipos de capim-elefante, considerando folhas (A) e colmos (B). (x) corresponde a dias de crescimento.

Figure 3 - Dry matter production from leaves $(A)$ and stems $(B)$ for three elephant grass cvs. growing through 126 days $(X)$. 

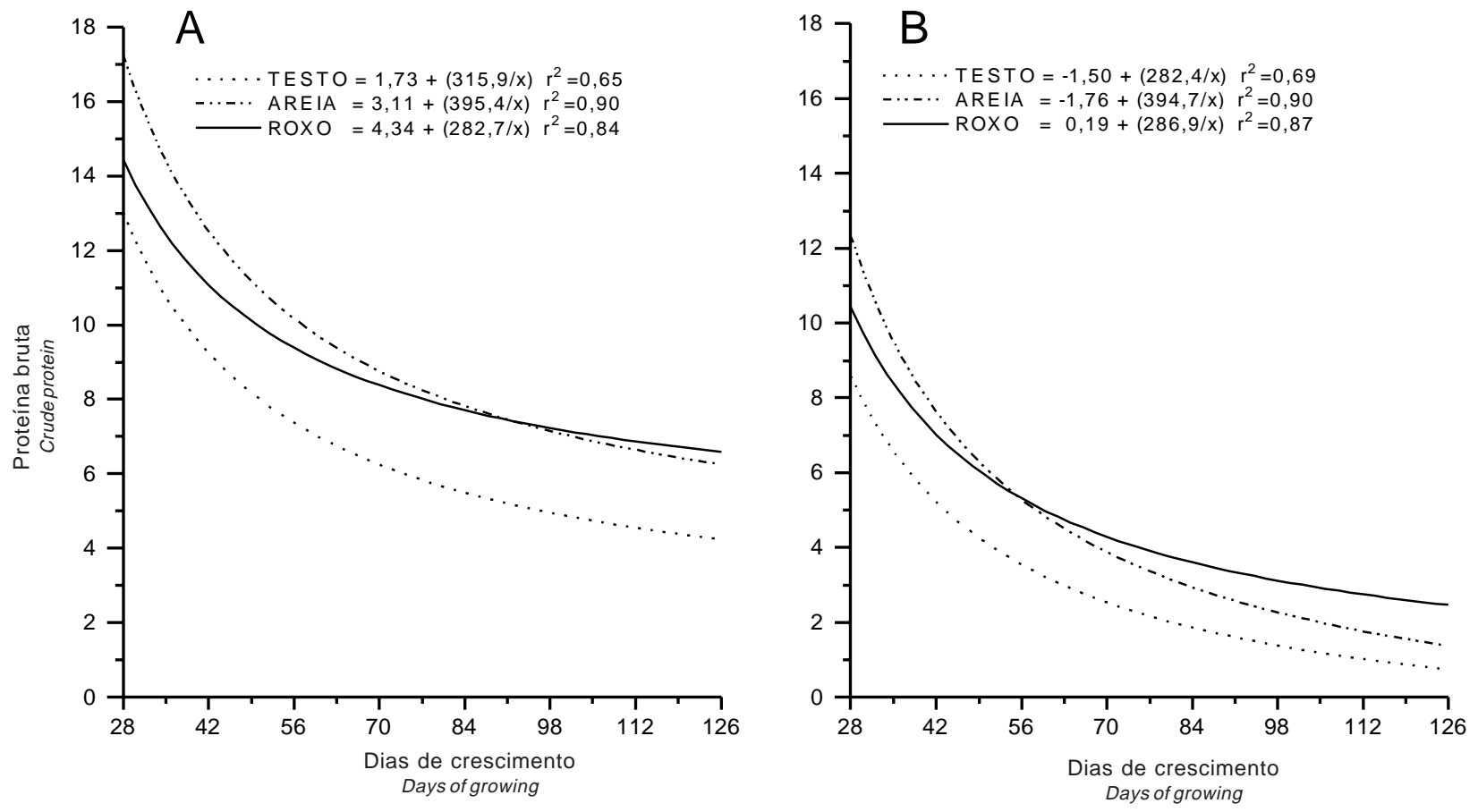

Figura 4 - Concentração de proteína bruta ao longo de 126 dias de crescimento, de três ecotipos de capim elefante, considerando folhas (A) e colmos (B). (x) corresponde a dias de crescimento.

Figure 4 - Crude protein content in leaves (A) and stems (B) of three elephant grass cvs. growing through 126 days $(X)$.

nantes são alimentados com forragens contendo baixos teores de proteína bruta $(\mathrm{N})$. Nesses casos, observa-se redução na disponibilidade de proteína para a síntese da biota ruminal e, conseqüentemente, menor disponibilidade de aminoácidos para o ruminante (MERCHEN e BOURQUIN, 1994). O desempenho pode ainda ser mais comprometido, se a digestibilidade da forragem também for baixa, pois reduz a quantidade de matéria orgânica digestível, influenciando a disponibilidade de energia para o metabolismo dos microorganismos do rúmen. Não se pode desconsiderar que a menor participação de $\mathrm{N}$, na composição das forrageiras tropicais, decorre da maior eficiência com que as plantas $\mathrm{C}_{4}$ utilizam o $\mathrm{N}$ para converter $\mathrm{CO}_{2}$, ou seja, com menos $\mathrm{N}$ disponível depositam maior quantidade de matéria seca. Isto explica em parte, também, porque as gramíneas tropicais são mais tolerantes a solos menos férteis e, por outro lado, apresentam menor teor de $\mathrm{N}$ na composição da MS (NELSON e MOSER, 1994).

Com a maturação fisiológica das plantas, observam-se modificações estruturais e químicas nos tecidos, que se refletem principalmente na redução da digestibilidade. Entre as barreiras estruturais, a cutícula e a epiderme podem ser consideradas como de gran- de importância, pela presença de compostos resistentes à digestão como $n$-alcanos e sílica, além da própria sinuosidade da parede das células da epiderme. Sabe-se, por exemplo, que elevadas temperaturas, luminosidade e pouca umidade aumentam a espessura da cutícula na epiderme das folhas, sendo a concentração maior na face abaxial das folhas (WILSON, 1993). Isto também foi observado nos cultivares de capim-elefante do presente estudo (ALVES DE BRITO, 1997). Em gramíneas, a digestibilidade da cutícula e da epiderme como um todo pode ser considerada muito baixa ou praticamente nula (AKIN e BURDICK, 1981; AKIN et al., 1983; e MAGAI et al., 1994). Aproveitando-se esta característica, tem sido proposta a utilização dos $n$ alcanos como marcadores biológicos em ensaios de digestão, ingestão e determinação da composição botânica em ensaios de pastejo (McMENIMAN, 1997). Em várias espécies de gramíneas, são encontrados, também, elevados níveis de sílica na epiderme, principalmente na forma de corpos silicosos e tricomas. Estas estruturas, resistentes à digestão, foram abundantemente encontradas nos três cultivares de capimelefante do presente estudo (ALVES DE BRITO, 1997). Entretanto, a cutícula pode ser transposta, mes- 
Tabela 2 - Equações de ajuste relacionando os efeitos do período de crescimento sobre algumas variáveis observadas nos três cultivares de capim-elefante

Table 2 - Fitted curves for the effect of growing period over some variables in three elephant grass cvs

\begin{tabular}{|c|c|c|c|}
\hline $\begin{array}{l}\text { Parâmetro } \\
\text { Parameter }\end{array}$ & & $\begin{array}{l}\left.\text { Equação de ajuste (Max. } \mathrm{r}^{2}\right) \\
\text { Fitted curve }\end{array}$ & \\
\hline & & cv.TESTO & $\mathrm{r}^{2}$ \\
\hline Altura (cm) & & $=-32,90+6,14(\operatorname{dias})-0,052\left(\operatorname{dias}^{2}\right)+0,000188\left(\operatorname{dias}^{3}\right)$ & 0,91 \\
\hline Height & & & \\
\hline $\mathrm{FDN}(\%)$ & Folha & $=64,60+0,264(\operatorname{dias})-0,00137\left(\operatorname{dias}^{2}\right)$ & 0,62 \\
\hline$N D F$ & Colmo & $=50,92+0,603($ dias $)-0,00292\left(\operatorname{dias}^{2}\right)$ & 0,94 \\
\hline Degradação da FDN (\%) ${ }^{2}$ & Folha & $=76,69-0,522($ dias $)+0,00224\left(\operatorname{dias}^{2}\right)$ & 0,84 \\
\hline NDF degradation & Colmo & $=85,27-0,769($ dias $)+0,00208\left(\operatorname{dias}^{2}\right)$ & 0,96 \\
\hline Degradação da MS (\%) ${ }^{2}$ & Folha & $=85,31-0,561(\operatorname{dias})+0,00251\left(\operatorname{dias}^{2}\right)$ & 0,94 \\
\hline DM degradation & Colmo & $=101,5-0,952($ dias $)+0,00342\left(\operatorname{dias}^{2}\right)$ & 0,97 \\
\hline $\operatorname{Lignina}^{3}(\%)$ & Folha & $=10,28+0,128(\operatorname{dias})-0,000489\left(\operatorname{dias}^{2}\right)$ & 0,98 \\
\hline Lignin & Colmo & $=4,89+0,165($ dias $)-0,000485\left(\operatorname{dias}^{2}\right)$ & 0,99 \\
\hline & & cv. AREIA & \\
\hline Altura (cm) & & $=-120,97+7,65(\operatorname{dias})-0,064\left(\operatorname{dias}^{2}\right)+0,00022\left(\operatorname{dias}^{3}\right)$ & 0,98 \\
\hline Height & & & \\
\hline $\mathrm{FDN}(\%)$ & Folha & $=41,04+0,767(\operatorname{dias})-0,00394\left(\operatorname{dias}^{2}\right)$ & 0,93 \\
\hline$N D F$ & Colmo & $=35,56+0,993($ dias $)-0,00499\left(\operatorname{dias}^{2}\right)$ & 0,97 \\
\hline Degradação da FDN (\%) ${ }^{2}$ & Folha & $=68,43-0,153($ dias $)$ & 0,75 \\
\hline NDF degradation & Colmo & $=68,60-0,344($ dias $)$ & 0,92 \\
\hline Degradação da MS (\%) ${ }^{2}$ & Folha & $=92,53-0,560($ dias $)+0,00215\left(\operatorname{dias}^{2}\right)$ & 0,96 \\
\hline DM digestibility & Colmo & $=103,9-0,991(\operatorname{dias})+0,00359\left(\operatorname{dias}^{2}\right)$ & 0,97 \\
\hline $\operatorname{Lignina}^{3}(\%)$ & Folha & $=8,87+0,122($ dias $)-0,000419\left(\operatorname{dias}^{2}\right)$ & 0,98 \\
\hline Lignin & Colmo & $=3,66+0,182($ dias $)-0,000512\left(\operatorname{dias}^{2}\right)$ & 0,97 \\
\hline & & cv. ROXO & \\
\hline Altura (cm) & & $=-77,79+6,42(\operatorname{dias})-0,054\left(\operatorname{dias}^{2}\right)+0,000198\left(\operatorname{dias}^{3}\right)$ & 0,98 \\
\hline Height & & & \\
\hline $\mathrm{FDN}(\%)$ & Folha & $=47,41+0,567(\operatorname{dias})-0,00314\left(\operatorname{dias}^{2}\right)$ & 0,85 \\
\hline$N D F$ & Colmo & $=49,75+0,509(\operatorname{dias})-0,00217\left(\operatorname{dias}^{2}\right)$ & 0,89 \\
\hline Degradação da FDN (\%) ${ }^{2}$ & Folha & $=84,07-1,12(\operatorname{dias})+0,0148\left(\operatorname{dias}^{2}\right)-0,00007\left(\operatorname{dias}^{3}\right)$ & 0,87 \\
\hline NDF degradation & Colmo & $=42,17+1,06(\operatorname{dias})-0,0219\left(\operatorname{dias}^{2}\right)-0,0001\left(\operatorname{dias}^{3}\right)$ & 0,95 \\
\hline Degradação da MS (\%) ${ }^{2}$ & Folha & $=85,38-0,401($ dias $)+0,00135\left(\operatorname{dias}^{2}\right)$ & 0,83 \\
\hline DM degradation & Colmo & $=93,91-0,656($ dias $)+0,00174\left(\operatorname{dias}^{2}\right)$ & 0,98 \\
\hline $\operatorname{Lignina}^{3}(\%)$ & Folha & $=10,43+0,128(\operatorname{dias})-0,000430\left(\operatorname{dias}^{2}\right)$ & 0,95 \\
\hline Lignin & Colmo & $=12,15-0,142(\operatorname{dias})+0,00313\left(\operatorname{dias}^{2}\right)-0,000013\left(\operatorname{dias}^{3}\right)$ & 0,99 \\
\hline
\end{tabular}

Folha (leaf); Colmo (stem).

1 Amostras submetidas à digestão em solução detergente neutro por 40 minutos em autoclave $\left(120^{\circ} \mathrm{C}\right)$.

2 Dados obtidos a partir da incubação das amostras em sacos de nylon, por 48 horas, utilizando-se três bovinos adultos dotados de cânula ruminal.

3 Denominada de lignina de Klason, contendo, além da lignina, alguns elementos minerais e sílica. Para esta determinação, as amostras, em duplicata, foram submetidas à pré-hidrólise em ácido sulfúrico $12 \mathrm{M}$ durante 1 hora. Após, o ácido foi diluído para $0,4 \mathrm{M}$ e o material submetido à nova hidrólise em autoclave de bancada durante 60 minutos a $120^{\circ} \mathrm{C}$.

1 Samples were subjected to digestion in neutral detergent solution ( 40 minutes, $120^{\circ} \mathrm{C}$ ).

2 Data were obtained from the nylon bag technique with samples incubation (48 h) in three cannulated adults bovine.

3 This residue (Klason lignin) hold other minerals and silica beyond lignin. The samples were subjected to a acid hydrolysis $\left(\mathrm{H}_{2} \mathrm{SO}_{4} 12 \mathrm{M}-1 \mathrm{~h}\right.$ at room temperature) and after the acid was diluted to $0,4 \mathrm{M}$ and hydrolysed again $\left(1 \mathrm{~h}-120^{\circ} \mathrm{C}\right)$.

mo que represente importante barreira para o acesso dos microorganismos aos tecidos mais profundos. $\mathrm{O}$ autor observou, ainda, que o poro dos estômatos representa oportunidade de acesso da biota ruminal para a digestão do mesofilo, tendo por início a câmara subestomática.

As implicações mais claras do envelhecimento dos tecidos de forrageiras refletem-se na digestão do material. No presente trabalho, observou-se que, com a ampliação do período de crescimento, ocorreu intensa redução na digestão da MS e FDN tanto no colmo quanto na folha de todos os materiais estudados. Deve-se considerar que a qualidade final da forragem depende da qualidade das folhas e do colmo e da relação folha:colmo. Considera-se que colmos de gramíneas em estádio imaturo apresentam elevado potencial digestivo, em muitos casos superior ao das folhas (NELSON e MOSER, 1994), o que tam- 
1366 Rev. bras. zootec.

bém foi observado, no presente estudo, com os cultivares de capim-elefante. Entretanto, com a ampliação do período de crescimento das plantas, observouse que o colmo apresentou redução mais acentuada na digestibilidade em relação às folhas (Tabela 1 e 2). $\mathrm{Na}$ média dos três cultivares, a digestibilidade da matéria seca das folhas aos 28 e 126 dias foi de 75,7 e $54,9 \%$ e para o colmo, 76,1 e 37,8\%. Já a digestibilidade da FDN das folhas, para o mesmo período, foi de 63,5 e 43,6\% e para o colmo, 58,0 e $25,1 \%$. Portanto, no colmo, as modificações estruturais ou químicas que ocorrem nos tecidos influem mais na digestibilidade deste material; parte disso pode ser decorrente do espessamento e da lignificação da parede celular. Soma-se a isto a anatomia do colmo, cuja estrutura é formada por grande número de feixes vasculares, quando comparada com os demais órgãos da planta, resultando em menor proporção de tecidos mais digestíveis (WILSON 1993). O colmo é formado por grande número de células com paredes espessadas, altamente lignificadas, cuja estrutura está intimamente ligada às funções de condução dos fluidos da planta e sustentação da parte aérea. Por outro lado, os feixes vasculares estão circundados pela bainha esclerenquimática, uma estrutura resistente, composta principalmente por fibras, cuja função é impedir injúrias aos feixes. Pode-se considerar, então, que este complexo represente considerável barreira para a digestão dos tecidos, dificultando a ação dos microorganismo ruminais. O maior número de feixes vasculares do colmo demanda maior tempo de ruminação, afetando negativamente o consumo e a digestibilidade (WILSON, 1993; WILSON, 1997). Deve-se ressaltar que as $C_{4}$ apresentam maior número de feixes vasculares em relação às temperadas, sendo em parte a razão pela qual as tropicais são mais drasticamente afetadas com o envelhecimento dos tecidos (WILSON 1993).

Barreiras estruturais como a cutícula, epiderme, feixes vasculares, entre outros, apresentam distribuição distinta ao longo dos diferentes órgãos da planta. ALVES DE BRITO (1997) descreveu que a quilha foi a região da folha mais intensamente lignificada, o que pode ser em parte compreendido pela função de suporte mecânico desempenhada pela quilha nas folhas longas do capim-elefante. Ainda assim, é questionável o nível de comprometimento na digestão do capim-elefante, determinado pelo grau de lignificação da quilha. Isto somente será mais claro quando se quantificar a participação destes tecidos, tanto em área ocupada quanto em contribuição para o peso seco total.
$\mathrm{Na}$ alimentação de ruminantes, os efeitos negativos da presença de barreiras físicas pode ser, em parte, minimizado pelo ato da ruminação. A ruminação promove a redução do tamanho das partículas de alimento, permitindo aumentar consideravelmente a superfície exposta para a ação da biota ruminal. $\mathrm{O}$ processo de digestão pode ser considerado tempo dependente, determinando que qualquer dificuldade na digestão eleve o tempo de permanência dos alimentos no trato digestivo, reduzindo, assim, o consumo e a disponibilidade de nutrientes para a produção animal.

A presença da lignina no complexo lignocelulósico tem sido considerada a maior barreira química para digestão das forragens. Apesar do avanço observado nos últimos tempos com relação à sua estrutura, gênese e degradação, seus efeitos sobre a digestão ruminal não podem ser considerados totalmente compreendidos. A lignina é classicamente definida como um polímero natural de unidades fenil-propano, tendo como precursores os álcoois coniferílico, sinapílico, e p-coumarilico (SARKANEN e LUDWIG, 1971). Estas unidades fenólicas podem se associar, formando agregados altamente condensados, ou ainda se associar a carboidratos (SARKANEN e LUDWIG, 1971; JUNG, 1989). A ligação em $O-5$ da arabinose com o ácido ferúlico parece ser a principal forma de associação entre a hemicelulose e a lignina (CHESSON et al., 1983; ATSUSHI et al., 1984; AZUMA et al., 1985; e JUNG, 1989). Admite-se que, nas plantas imaturas, o menor grau de condensação da lignina compromete menos a digestão dos tecidos. Entretanto, a maturação fisiológica do vegetal possibilita a formação de complexos de elevado peso molecular, os quais envolvem a hemicelulose e a celulose. Sua associação com a hemicelulose impede a ação das enzimas que atuam na degradação do carboidratos, já que dificulta tanto o acesso quanto o adequado acoplamento ao substrato (carboidrato). Além disso, estudos têm demonstrado que os compostos fenólicos derivados da lignina, como a vanilina, o ácido $p$-coumárico e ácido ferúlico, inibem a aderência e a digestão da fibra por culturas puras ou mistas de microorganismos ruminais (AKIN, 1982; CHESSON et al., 1982; VAREL e JUNG, 1986; e AKIN et al., 1988). No presente estudo, foi observado que a maturação das plantas dos três cultivares promoveu considerável acúmulo de lignina tanto nas folhas quanto no colmo (Tabelas 1 e 2). O conteúdo médio de lignina nos três cultivares, aos 28 dias, foi de $13,1 \pm 1,07 \%$ nas folhas e $9,4 \pm 0,71 \%$ no colmo, enquanto aos 126 dias, $18,8 \pm 1,15 \%$ e $18,2 \pm 0,25 \%$. En- 
tretanto, parece que o aumento no conteúdo de lignina não é a única causa a contribuir para a redução na digestibilidade da matéria seca, como conseqüência da maturação dos tecidos. Isto pode ser considerado, admitindo-se as seguintes pressuposições: a) a lignina de Klason, como determinada no presente estudo, seja composta de elementos não digestíveis; $b$ ) a digestibilidade média dos três cultivares aos 28 dias foi de $75,7 \%$ nas folhas e $76,2 \%$ no colmo, enquanto aos 126 dias, 54,9 e 37,8\% (Tabela 1); c) o que sobra da digestão, descontada a lignina, é considerado carboidrato não-digerido. Dessa maneira, em $100 \mathrm{~g}$ de matéria seca de folhas cortadas com 28 dias, ter-se-ão $24,3 \%$ de resíduo não-digerido, dos quais, subtraindo-se $13,1 \%$ de lignina, restariam $11,2 \%$ de carboidratos, que por várias razões não foram digeridos pela biota ruminal. Se isto for aplicado ao colmo no mesmo período, têm-se $14,4 \%$. Já aos 126 dias, ter-se-ão 26,3\% de carboidratos retidos em tecidos das folhas e $44,0 \%$ nos tecidos do colmo. Portanto, em um primeiro momento, parece que os efeitos negativos da lignificação são mais acentuados no colmo que nas folhas, mesmo que o conteúdo aos 126 dias de crescimento $( \pm 18,5 \%)$ seja praticamente o mesmo nas duas frações. Isto aponta para que, além das restrições que determinados componentes químicos podem apresentar na digestão da biomassa, outros fatores, como o arranjo anatômico apresentado por determinadas estruturas da planta, podem ser acrescidos. No capim-elefante, a disposição dos tecidos no colmo é bastante distinta do arranjo apresentado nas folhas (ALVES DE BRITO, 1997), o que permite concluir que somente o conteúdo de lignina não é suficiente para explicar a redução na digestão dos tecidos do colmo desta forrageira, pois a digestão nos ruminantes depende da interação dos microorganismo da biota ruminal com a partícula de alimento a ser digerida (CHESSON, 1993; McALLISTER, et al., 1994). Portanto, barreiras estruturais que dificultem o acesso dos microorganismos a partícula de alimento certamente afetarão a digestão das forragens.

Algumas das variáveis estudadas encontram-se fortemente correlacionadas. Assim, o período de crescimento afeta drasticamente a digestibilidade da matéria seca $(r=-0,88)$ e da FDN $(r=-0,83)$ (Tabela 3). Isto ocorre paralelamente ao incremento na concentração de FDN $(r=0,72)$ e lignina $(r=0,84)$, os quais refletem o espessamento da parede celular e o aumento na área de tecido lignificado, como descrito por ALVES DE BRITO (1997). Já a concentração de lignina esteve negativamente associada à digestibilidade da matéria seca $(\mathrm{r}=$ $0,72)$ e da FDN ( $r=-0,59)$ (Tabela 3 ), sugerindo que outros fatores, como o arranjo e a natureza dos tecidos, contribuem para reduzir a digestão (WILSON, 1993, WILSON, 1997; e ALVES DE BRITO, 1997).

Vale lembrar que, apesar dos avanços obtidos, dimensionar com precisão o grau de restrição apresentados pelos fatores químicos ou pelo arranjo anatômico ainda permanece um desafio.

\begin{tabular}{|c|c|c|c|c|}
\hline $\begin{array}{l}\text { Variável } \\
\text { Variable }\end{array}$ & Idade (dias) & $\operatorname{FDN}(\%)$ & Digestibilidade da FDN (\%) & Digestibilidade da MS (\%) \\
\hline Variable & Age (days) & NDF & NDF disappearance & DM disappearance \\
\hline $\begin{array}{l}\mathrm{FDN}(\%) \\
N D F\end{array}$ & 0,72 & - & - & - \\
\hline $\begin{array}{l}\text { Degradação da FDN }(\%) \\
N D F \text { degradation }\end{array}$ & $-0,83$ & $-0,71$ & - & - \\
\hline $\begin{array}{l}\text { Degradação da MS (\%) } \\
\text { DM degradation }\end{array}$ & $-0,88$ & $-0,88$ & 0,95 & - \\
\hline $\begin{array}{l}\text { Lignina }(\%) \\
\text { Lignin }\end{array}$ & 0,84 & 0,61 & $-0,59$ & $-0,72$ \\
\hline
\end{tabular}




\section{Conclusões}

A diferença entre cultivares de capim-elefante, principalmente quanto à relação folha:colmo, só foi detectada no período inicial de crescimento.

Com a maturação do capim-elefante, os níveis de proteína bruta reduzem tanto nas folhas quanto no colmo, ocorrendo níveis mais críticos a partir de 56 dias.

A maturação dos tecidos está correlacionada diretamente com o incremento nas concentração de FDN e lignina e inversamente com a digestibilidade da MS e FDN.

Com quatro semanas de crescimento, os tecidos do colmo apresentam digestibilidade igual ou superior aos tecidos da folha, enquanto aos 126 dias de crescimento a digestibilidade do colmo foi pelo menos $30 \%$ inferior à da folha.

A lignificação influencia a digestão do colmo mais drasticamente que a digestão das folhas.

Além da lignificação, outros fatores, como o arranjo estrutural, contribuem para limitar a digestão dos tecidos de capim-elefante pelos ruminantes.

\section{Referências Bibliográficas}

AUGUSTIN, E., TCACENCO, F.A. 1993. Isoenzymatic characterization of elephant grass (Pennisetum purpureum Schum.) germoplasm. Rev. Bras. Genet., 16(3):685-696.

AKIN, D.E. 1982. Forage cell wall degradation and p-coumaric, ferulic and sinapic acids. Agron. J., 74:424-428.

AKIN, D.E., BURDICK, D. 1981. Relationship of different histochemical types of lignified cell wall to forage digestibility. Crop Science, 21:577-581.

AKIN, D.E., RIGSBY, L.L. THEODOROU, M.K., HARTLEY, R.D. 1988. Population changes of fibrolytic rumen bacteria in the presence of phenolic acids and plant extracts. Anim. Feed Sci. Technol., 19:261-275.

AKIN, D.E., WILSON, J.R., WINDHAM, W.R. 1983. Site and rate of tissue digestion in leaves of $\mathrm{C}_{3}, \mathrm{C}_{4}$ and $\mathrm{C}_{3} / \mathrm{C}_{4}$ intermediate Panicum species. Crop Sci., 23:147-155.

ALMEIDA, E.X. Oferta de forragem de capim-elefante anão (Pennisetum purpureum SCHUM. cv. MOTT), dinâmica da pastagem e sua relação com o rendimento animal no alto Vale do Itajaí, Santa Catarina: Porto Alegre, RS: UFRGS, 1997. 112p. Tese (Doutorado em Zootecnia) - Universidade Federal do Rio Grande do Sul, 1997.

ALVES DE BRITO, C.J.F. Organização estrutural e degradação in vitro de tecidos em Pennisetum purpureum Schum. (Poaceae). Curitiba, PR: UFPR, 1997, 119p. Dissertação (Mestrado em Botânica) - Universidade Federal do Paraná, 1997.

ANDRADE, I.F., GOMIDE, J.A. 1971. Curva de crescimento e valor nutritivo de capim-elefante (Pennisetum purpureum Schum.) “A-146 Taiwan”. Rev. Ceres, 18(100):431-447.

ATSUSHI, K., AZUMA, J., KOSHIJIMA, T. 1984. Lignincarbohydrate complexes and phenolic acids in bagasse. Holzforschung, 38:141-149.

AZUMA, J., NOMURA, T., KOSHIJIMA, T. 1985. Lignin- carbohydrate complexes containing phenolic acids isolated from the culm of baboo. Agric. Biol. Chem., 49:2661-2669.

BOGDAN, A.V. 1977. Tropical pastures and fodder plants. London: Logman. 475p.

CHESSON, A. 1993. Mechanistic models of forage cell wall degradation. In: JUNG, H.G., BUXTON, D.R., HATFIELD, R.D., RALPH, J. (Eds.) Forage cell wall structure and digestibility. Madison, Wisconsin, USA: ASA/CSSA/SSSA. p.347-376.

CHESSON, A., GORDON, A.H., LOMAX, J.A. 1983. Substituent groups linked by alkali-labile bonds to arabinose and xylose residues of legume, grass, and cereal straw cell walls and their fate during digestion by rumen microorganisms. J. Sci. Food Agric., 34:1330-1340.

CHESSON, A., STEWART, C.S., WALLACE, R.J. 1982. Influence of plant phenolic acids on growth and cellulolytic activity of rumen bacteria. Appl. Environ. Microbiol., 44:497-603.

CORSI, M. Estudo da produtividade e do valor nutritivo do capim-elefante (Pennisetum purpureum - Schum.), variedade Napier submetido a diferentes frequências e alturas de corte. Piracicaba: ESALQ-USP, 1972. 139p. Tese (Doutorado) -Escola Superior de Agricultura "Luiz de Queiroz", 1972.

GONÇALVES, D.A. Produtividade e digestibilidade "in vitro" de dois cultivares de Pennisetum purpureum - Schum., submetidos a dois níveis de fertilidade, em diferentes estações do ano. Belo Horizonte, MG: UFMG, 1975. 115p. Dissertação (Mestrado) - Universidade Federal de Minas Gerais, 1975.

HATFIELD, R.D., JUNG, H.J.G., RALPH, J. et al. 1994. A comparision of the insoluble residues produced by klason lignin and acid detergent lignin procedures. J. Sci. Food Agric., 65:51-58.

HILLESHEIM, A. Manejo do gênero Pennisetum sob pastejo. In: SIMPÓSIO SOBRE MANEJO DA PASTAGEM, 9., 1988, Piracicaba. Anais... Piracicaba: FEALQ, 1988. p.77-108.

HILLESHEIM, A. Manejo do capim-elefante: corte. In: SIMPÓSIO SOBRE MANEJO DA PASTAGEM, 10, 1993, Piracicaba. Anais... Piracicaba: FEALQ, 1993. p.117-141.

HILLESHEIM, A., AGOSTINI, I., STUKER, H. 1995. Produção e manejo da pastagem do capim-elefante. Agropec. Catarinense, 8(3):48-53.

JACQUES, A.V.A. 1994. Caracteres morfo-fisiológicos e suas implicações com o manejo. In: CARVALHO, M.M., ALVIN, M.J., XAVIER, D.F., CARVALHO, L.A. (Eds.) Capimelefante: produção e utilização. Coronel Pacheco: EMBRAPA-CNPGL. p.31-47.

JUNG, H.G. 1989. Forages lignins and their effects on fiber digestibility. Agron. J., 81:33-38.

LAETSCH, W.M. 1974. The C4 syndrome: a structural analysis. Ann. Rev. Plant Physiol., 25:27-52.

MAGAI, M.M, SLEPER, D.A., BEUSELINCK, P.R. 1994. Degradation of three warm-season grasses in a prepared cellulase solution. Agon. J., 86:1049-1053.

McAllister, T.A., BAE, H.D., JONES, G.A., CHENG, K.J. 1994. Microbial attachment and feed digestion in the rumen. J. Anim. Sci., 72:3004-3018.

McMENIMAN, N.P. Methods of estimating intake of grazing animals. In: SIMPÓSIO SOBRE TÓPICOS ESPECIAIS EM ZOOTECNIA, 1997, Juiz de Fora. Anais... Juiz de Fora: SBZ, 1997. p.133-168.

MERCHEN, N.R., BOURQUIN, L.D. 1994. Process of digestion and factors influencing digestion of forage-based diets by ruminants. In: FAHEY JR., G.C. (Ed.) Forage quality, 
evaluation and utilization. Madison, Wisconsin, USA: ASA/ CSSA/SSSA. p.564-612.

NELSON C.J., MOSER, L.E. 1994. Plant factors affecting forage quality. In: FAHEY JR., G.R. (Ed.) Forage quality, evaluation, and utilization. Madison, Wisconsin, USA: ASA/ CSSA/SSSA. p.115-154.

PELL, A.N., DOANE, P.H., SCHOFIELD, P. In vitro digestibility and gas production. In: SIMPÓSIO SOBRE TÓPICOS ESPECIAIS EM ZOOTECNIA, 1997, Juiz de Fora. Anais... Juiz de Fora: SBZ, 1997. p.109-132.

SALERNO, A.R., VETTERLE, C.P., DESCHAMPS, F.C., FREITAS, E.A.G. 1989. Gramíneas forrageiras estivais perenes no baixo Vale do Itajaí. Florianópolis, EMPASC, 99p. (EMPASC, Boletim Técnico,49).

SARKANEN, K.V., LUDWIG, C.H. 1971. Lignins. New York: John Wiley \& Sons. 919p.

SILVA, J.D. 1981. Análise de alimentos (métodos químicos e biológicos). Viçosa: UFV, Imprensa Universitária. 166p.

THEANDER, O., WESTERLUND, E.1986. Studies on dietary fiber. 3. Improved procedures for analysis of dietary fiber. J. Agric. Food Chem., 34:330-336.

VAREL, V.H., JUNG, H.G. 1986. Influence of forage phenolics on ruminal fibrolytic bacteria and in vitro fiber degradation. Appl. Environ. Microbiol., 52:275-280.

VEIGA, J.B. 1994. Utilização do capim-elefante sob pastejo. In:
CARVALHO, M.M., ALVIN, M.J., XAVIER, D.F., CARVALHO, L.A. (Eds.) Capim-elefante: produção e utilização. Coronel Pacheco: EMBRAPA-CNPGL. p.165-193.

WEIMER, P.J. 1993. Microbial and molecular mechanisms of cell wall degradation - session synopsis. In: JUNG, H.G., BUXTON, D.R., HATFIELD, R.D., RALPH, J. (Eds.) Forage cell wall structure and digestibility. Madison, Wisconsin, USA: ASA/CSSA/SSSA. p.485-498.

WILSON, J.R. 1993. Organization of forage plant tissues. In: JUNG, H.G., BUXTON, D.R., HATFIELD, R.D., RALPH, J. (Eds.) Forage cell wall structure and digestibility. Madison, Wisconsin, USA: ASA/CSSA/SSSA. p.1-32.

WILSON, J.R. Structural and anatomical traits of forage influencing their nutritive value for ruminants. In: SIMPÓSIO INTERNACIONAL SOBRE PRODUÇÃO ANIMAL EM PASTEJO, 1997, Viçosa. Anais... Viçosa: DZO-UFV, 1997. p.173-208.

Recebido em: 12/05/98

Aceito em: 05/07/99 